\title{
Digitalization wildfire management near smart city
}

\author{
Mikhail Shilin ${ }^{1, *}$, Igor Sikarev ${ }^{1}$, Evgeniy Baikov ${ }^{1}$, George Gogoberidze ${ }^{2}$, and Oksana \\ Petrieva $^{3}$ \\ ${ }^{1}$ Russian State Hydrometeorological University, 79, Voronezhskaya str., 192007, St. Petersburg, \\ Russia \\ ${ }^{2}$ Murmansk Arctic State University, 15, Kapitana Egorova str., 183038, Murmansk, Russia \\ ${ }^{3}$ Saint-Petersburg University of State Fire Service of EMERCON of Russia, 149, Moskovskiy \\ prospect, 196051, St. Petersburg, Russia
}

\begin{abstract}
In article, there are considered results in digitalization wildfire management near smart city within Industry 4.0 period, when while climate change and Covid-19 pandemic. While research, there are used methods of data bases constructing, web-technologies and virtual reality tools. Also, there are used Foresight technologies, theory of decision making under uncertainties and risk management. As digitalization tools, authors propose to use online platforms, which integrate heterogeneous hardware and software resources in distributed networks. As study result, there is proposed a block model, that combines the investment objectives with cost of wildfire management near smart city adapted to Covid-19 pandemic and climate change conditions. Authors demonstrate usage of developed digital tools. The research results presented in this article has significant scientific novelty and can be useful for private investors, public environmental organizations of the civil sector and state environmental control bodies. They can be used in training and educational purposes, including development of Master's programs in environmental economics.
\end{abstract}

\section{Introduction}

Now, smart cities will be functioning not only in Industry 4.0 period, but and when while climate change and Covid-19 pandemic. Climate change will lead to serious increasing of wildfire near smart cities to and people have to be ready for it with digital technologies. Covid-19 pandemic heavily shocks global economics and cut many expenses including wildfire management (WFM) expenses near cities. This will be trend for recent decade. Recently, a wide range of information technologies are planning and implementing by many businesses [1-9]. Era of Industry 4.0 leads to serious information technological changes in smart cities activity, including natural risks management (NRM) [10-13], which requires the development of new tools, including practical learning area [14].

The purpose of this article is to develop digitalization tools for geo-information support systems (GISS) to WFM near smart cities while climate change and Covid-19 pandemic. In

\footnotetext{
* Corresponding author: mil.shilin@mail.ru
} 
this paper, we describe the development results of digital tools for such GISS within geoinformation management (GIM) paradigm [15], in large environmental projects [16-18] within environmental economics [19-23]. We paid significant attention to GISS within climate change and Covid-19 pandemic context, including the issues of information collection and processing $[11,12]$. Developed digital technologies for GISS to WFM near smart cities while climate change and Covid-19 pandemic, considered in this article, take these factors into account.

\section{Materials and Methods}

While study, we used theory of decision making under uncertainties, risk management approach, Foresight technologies, methods of data bases constructing, web-technologies and virtual reality (VR) tools. Also, we used big data and Internet of things technologies [16, 17, 24-26]. From the point of view of geo-information management, geo-space is structured to allocate the interconnected components of the solution space [19]. In research, we used data bases and tools of geo-information digital online platform EOS eos.com, including its Land Viewer (LV) product https://eos.com/lv/, which allows limited open access to operate space images from the Landsat- 8 and Sentinel-2 satellite systems.

\section{Results}

Using research results with Foresight technologies, we claim from the point of view of GIM, that in present conditions of climate change and Covid-19 pandemic, WFM near smart cities is to be carried out within the environmental economics as related set of natural-industrial projects (NIPs) within common space area and time period. In Fig.1, we present a block model of investment structure while such set of NIPs, which combines the investment objectives of NIPs (blocks 1-5) with cost of adequate geo-information support to WMF near smart cities (blocks 6-8), including NRM (block 7).

As study result, we propose to use geo-information distributed platforms (GIDPs) containing heterogeneous databases in the format of a multi-level architecture. We propose to use GIDP with three levels of data representation: "data - processing - interface". The advantages of such representation are the independence of the system from the number of software components included in each level and its own set of protocols and application interfaces for each level, which defines its own architecture.

To avoid the difficulties of multi-user access to data, we suggest to use a mechanism for pre-processing heterogeneous data, which includes a virtual data processor (VDP) and a data preparation unit (DPU). A VDP is a software module that allows uniform access to all system data via standard interfaces (protocols), while hiding the features of data placement, data structures and formats. A DPU aims at collecting and first processing the data requested by the user from the system. When using this mechanism, there is no need to convert data to the format used by the system, they remain in the original view and can be used locally by their applications. 


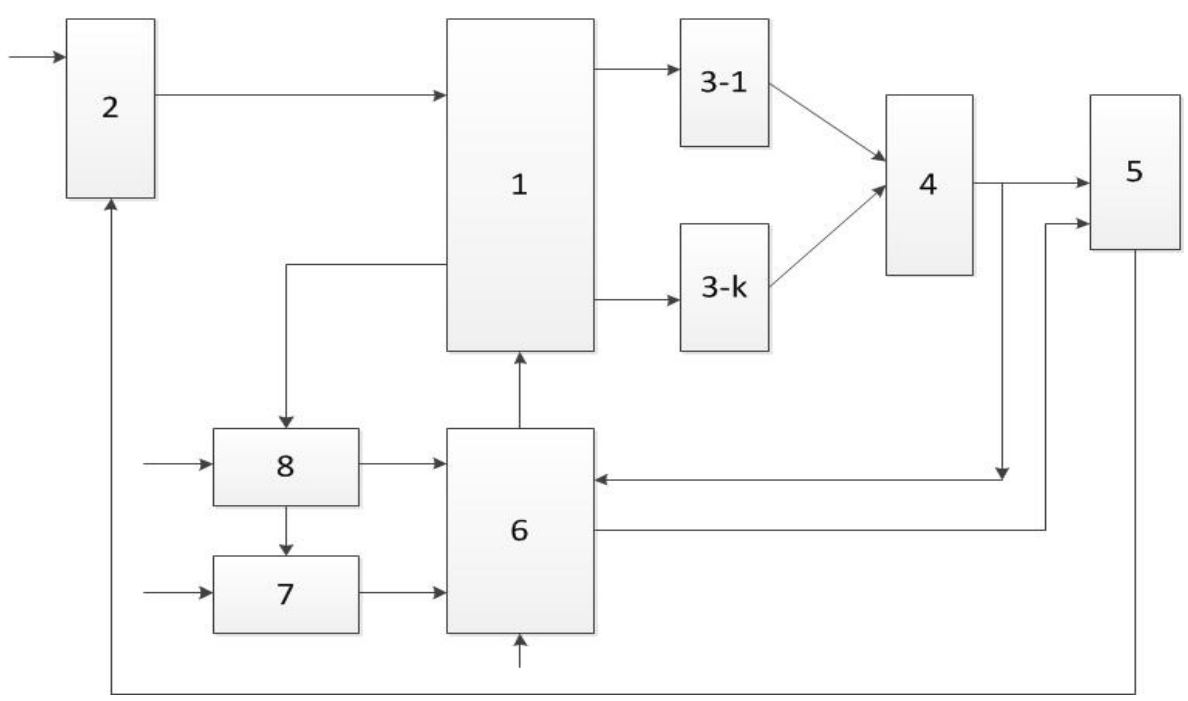

Fig. 1. Block model for investment structure within WMF near smart cities.

Where: 1 - block of distribution of resources; 2 - block of formation of resources; 3 block of formation of private income; 4 - block of formation of total income; 5 - block of formation of the investment share of resources; 6 - block of comparison with the permissible level of risk; 7-block of formation changing in time set of natural risks for WMF, including climate change risks and Covid-19 risks; 8 - block of environmental monitoring within WMF while climate change andCovid-19 pandemic conditions

On basement of above mentioned block model, we propose to develop the geoinformation support system (GISS) for WMF with combined structure for access, storage and analysis of information from open geo-spatial data sources, including archives and operative mode web tools.

Our analysis shows that the largest part of the cost of geo-information support is the environmental monitoring (block 8), the essence of which is determined by the content of block 7. Significant part of the cost in block 8 is the cost of hardware and software, which varies significantly for different NIPs. Reducing the cost of GISS for WMF is an important direction of GISS construction.

As a result of the research, performed using foresight technologies, we suggest to use geo-information distributed online platforms (GIDOPs) with cloud technologies (CT) as the main technological solutions for GISS construction. In this article, we recommend to use GIDOP EOS eos.com, including its Land Viewer (LV) product https://eos.com/lv/, which allows to operate with space images from the Landsat- 8 and Sentinel-2 satellite systems with limited open access.

Let's go to examples. In figures 2-6, we show the sequential operations performed for the largest wildfires in Australia in the fall of 2019 near cities with using of GIDOP EOS and its tools. In the figures 2-6, we combine on one image the first and second mid-infrared (1566$1651 \mathrm{~nm}$ and 2107-2294 nm, respectively) and red (636-673 nm) channels, which allowed to identify the wildfires zones on combined space image as reddish colored areas on greening plane. 


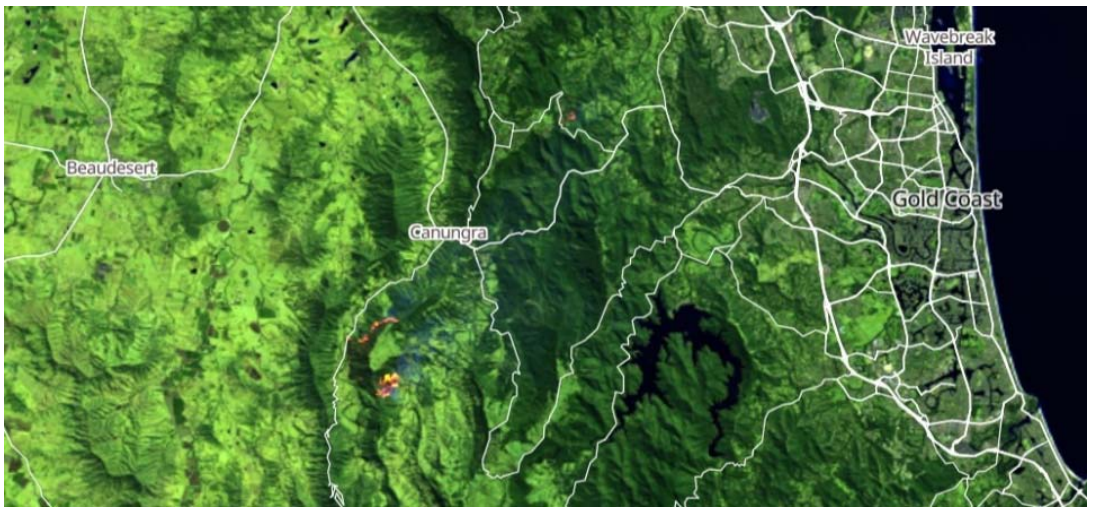

Fig. 2. Space image with wildfire zones (reddish), $3^{\text {rd }}$ September 2019, Australia.

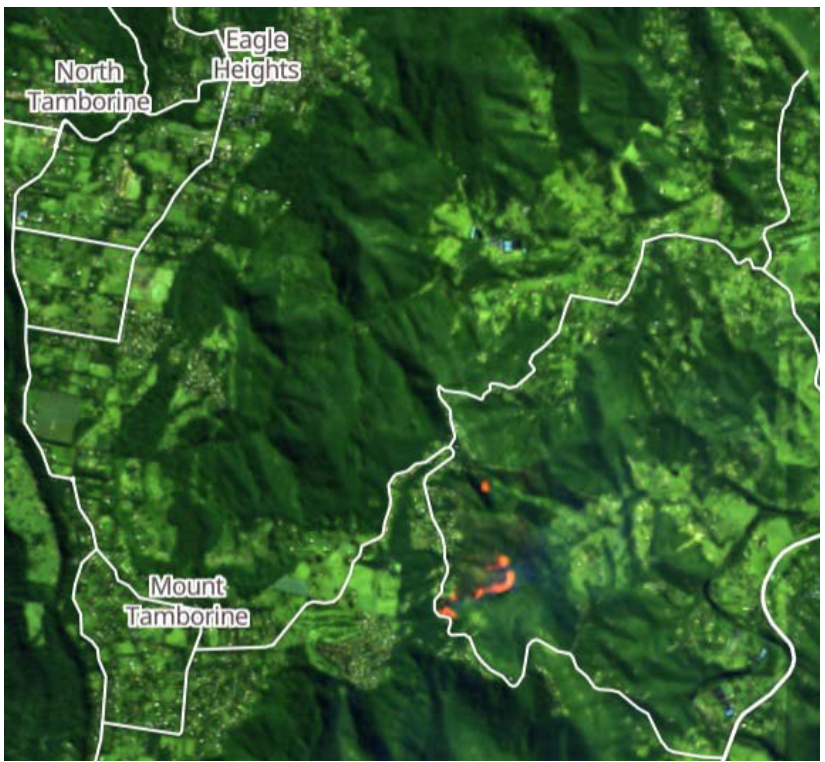

Fig. 3. Enlarge space image with wildfire zones, $3^{\text {rd }}$ September 2019, Australia.

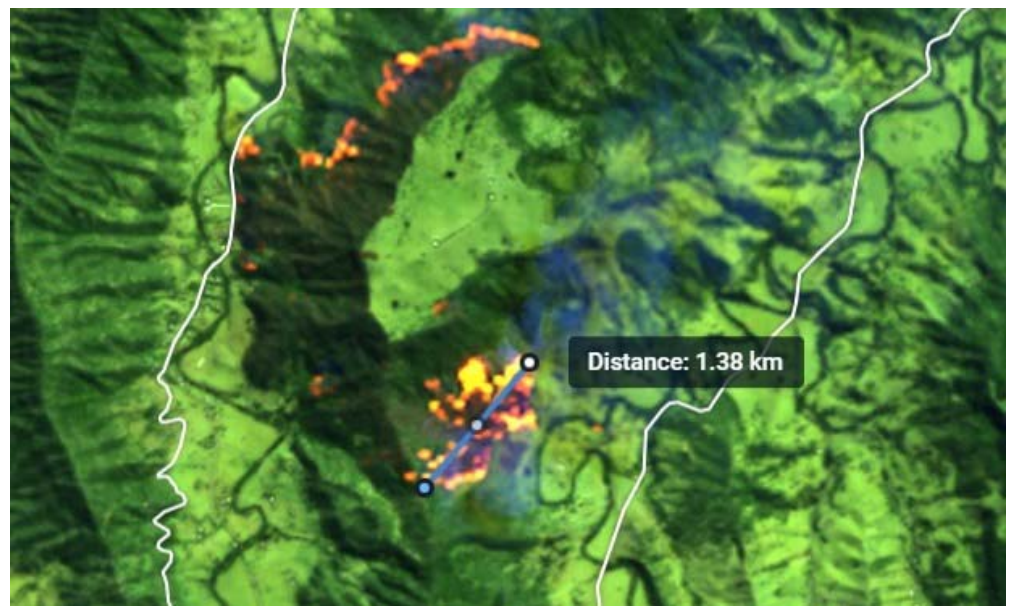

Fig. 4. Enlarge image of wildfire area and measuring its characteristics. 


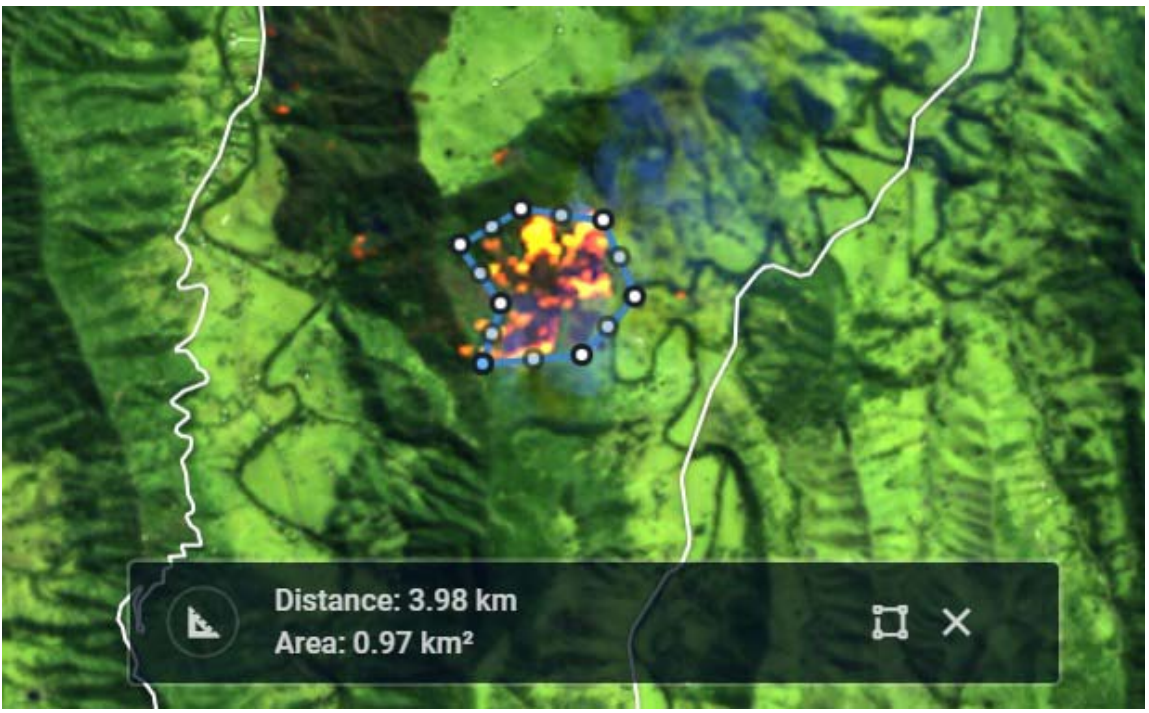

Fig. 5. Enlarge image of wildfire area and measuring its characteristics.

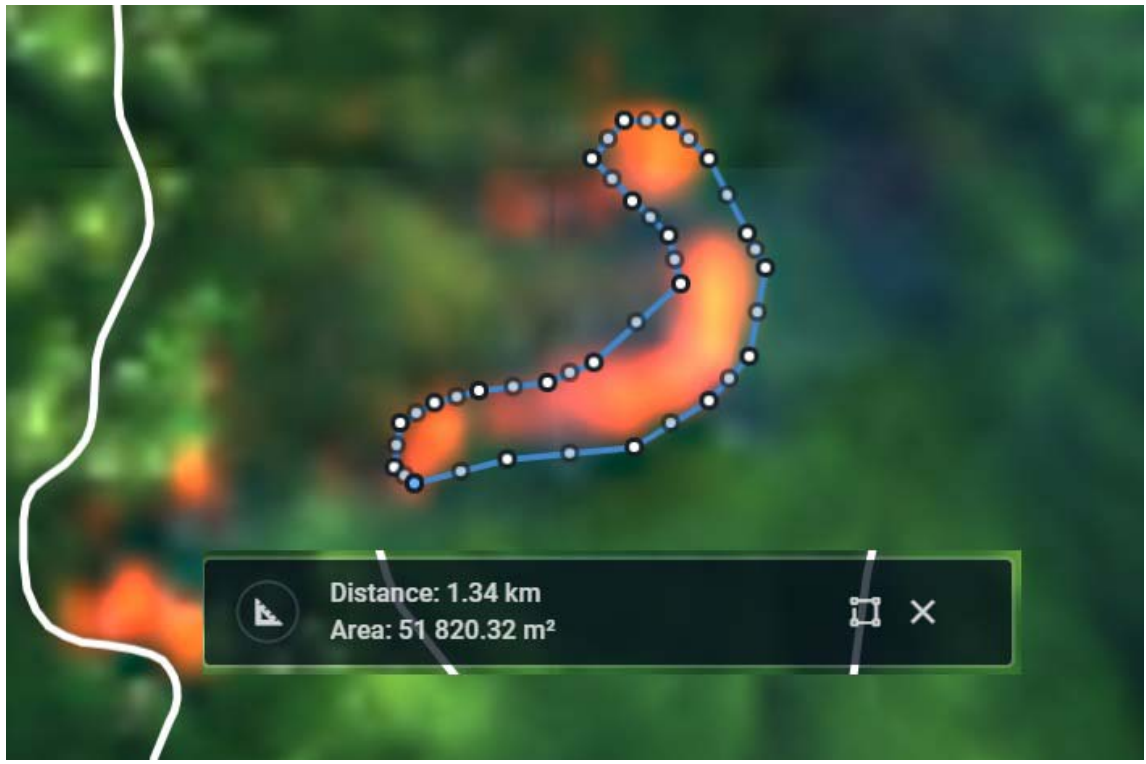

Fig. 6. Enlarge image of wildfire area and measuring its characteristics.

Then, we obtained data for WFM from figures 2-6, using GIDOP EOS's data bases and tools, and combining on one image the first and second mid-infrared (1566-1651 nm and 2107-2294 nm, respectively) and red (636-673 nm) channels, to see wildfires zones on combined space image as reddish colored areas on greening plane. Note, discussion of those data using for WFM is not task of this article.

\section{Discussion}

Proposed GISS to WMF near smart cities while climate change and Covid-19 pandemic can be used in educational and training purposes. Note, tasks of training will require a developed 
learning base within special geo-information systems (GIS) laboratory. It can be undergoing with virtual reality (VR) technologies (Popov, 2019), that can reduce total cost of learning process.

\section{Conclusions}

In paper, we present results for digitalization of WMF near smart cities while climate change and Covid-19 pandemic. While research, we used Foresight technologies, theory of decision, risk management, methods of data bases constructing, web-technologies and virtual reality tools. As study result, we proposed a block model, that combines the investment objectives with cost of adequate WMF near smart cities adapted to climate change and Covid-19 pandemic conditions. As research result, we suggest to use GIDOP Earth and GIDOP EOS, including its LV product, as the main technological tools within GISS to WMF near smart cities adapted to climate change and Covid-19 pandemic conditions. We demonstrate possibilities of proposed GISS. As essential result, we propose to use developed GISS for educational and training purposes. The research results presented in this article has significant scientific novelty and can be useful for private investors, public environmental organizations of the civil sector and state environmental control bodies. They can be used in training and educational purposes, including development of Master's programs in environmental economics.

\section{Acknowledgements}

While research, Associate Professor Valery M. Abramov, director of Arctic and Subarctic Institute at Russian State Hydrometeorological University (ASI RSHU), gave us very useful consulting. For preliminary discussion and data exchange while this research, we use the platform https://www.researchgate.net/profile/Valery_Abramov2/.

\section{References}

1. A. Sokolov, V. Abramov, E. Istomin, E. Korinets, V. Bolshakov, T. Vekshina, IOP Conference Series: Materials Science and Engineering 940(1), 012003 (2020)

2. I.V. Ilin, A.V. Izotov, S.V. Shirokova, O.V. Rostova, A.I. Levina, Proceedings of 2017 20th IEEE International Conference on Soft Computing and Measurements, SCM 2017 7970732, 812-814 (2017)

3. A.G. Sokolov, V.M. Abramov, S.V. Lukyanov, et al., Proceedings of 34th IBIMA Conference. Vision 2025: Education Excellence and Management of Innovations Through Sustainable Economic Competitive Advantage, 10763-10771 (2019)

4. A. Poljanskihh, A. Levina, A. Dubgorn, MATEC Web of Conferences 193, 05065 (2018)

5. A. Dubgorn, M.N. Abdelwahab, A. Borremans, I. Zaychenko, Proceedings of the 33rd International Business Information Management Association Conference, IBIMA 2019: Education Excellence and Innovation Management through Vision 2020, 9677-9682 (2019)

6. N.S. Frolova, V.M. Abramov, E.P. Istomin, N.N. Popov, M.B. Shilin, S.V. Lukyanov, V.A. Golosovskaya, D.V. Drabenko, Proceedings of 34th IBIMA Conference: 13-14 November 2019, Madrid, Spain. Vision 2025: Education Excellence and Management of Innovations Through Sustainable Economic Competitive Advantage, 10132-10141 (2019) 
7. S.V. Lukyanov, V.M. Abramov, A.S. Averkiev, A.E. Rybalko, Yu.A. Tatarenko, N.S. Frolova, O.I. Shevchuk, Proceedings of the 33rd International Business Information Management Association Conference, IBIMA 2019: Education Excellence and Innovation Management through Vision 2020, 7112-7122 (2019)

8. S. Maydanova, I. Ilin, A. Lepekhin, Proceedings of the 33rd International Business Information Management Association Conference, IBIMA 2019: Education Excellence and Innovation Management through Vision 2020, 5103-5111 (2019)

9. V. Orlova, I. Ilin, S. Shirokova, MATEC Web of Conferences 193 (2018)

10. V.A. Drabenko, E.P. Istomin, V.M. Abramov, A.G. Sokolov, E.M. Korinets, N.N. Popov, V.A. Bolshakov, V.A. Golosovskaya, Proceedings of 34th IBIMA Conference. Vision 2025: Education Excellence and Management of Innovations Through Sustainable Economic Competitive Advantage, 9878-9885 (2019)

11. J.A. Garcia, V.M. Abramov, E.P. Istomin, 18th International Multidisciplinary Scientific GeoConference Surveying Geology and Mining Ecology Management, SGEM Bulgaria 18(2.2), 261-268 (2018)

12. V.M. Abramov, I.V. Aleshin, V.G. Burlov, et al., Proceedings of the 33rd International Business Information Management Association Conference, IBIMA 2019: Education Excellence and Innovation Management through Vision 2020, 7053-7061 (2019)

13. E.P. Istomin, V.G. Burlov, V.M. Abramov, A.A. Fokicheva, A.G. Sokolov, 18th International Multidisciplinary Scientific GeoConference Surveying Geology and Mining Ecology Management, SGEM Bulgaria 18(2.2), 377-384 (2018)

14. N.N. Popov, V.M. Abramov, E.M. Korinets, E.P. Istomin, A.G. Sokolov, V.A. Bolshakov, T.V. Vekshina, Proceedings of 34th IBIMA Conference. Vision 2025: Education Excellence and Management of Innovations Through Sustainable Economic Competitive Advantage, 9409-9417 (2019)

15. A.A. Fokicheva, E.P. Istomin, A.G. Sokolov, V.M. Abramov, N.N. Popov, 16th Informatics, geoinformatics and remote sensing conference proceedings, International Multidisciplinary Scientific GeoConference Surveying Geology and Mining Ecology Management, SGEM Bulgaria 4(2), 601-608 (2016)

16. E.A. Yaily, V.M. Abramov, E.P. Istomin, S.I. Bidenko, V.V. Novikov, S.I. Bidenko, 19th International Multidisciplinary Scientific GeoConference Surveying Geology and Mining Ecology Management, SGEM Bulgaria 19(2.1), 793-799. (2019).

17. A.N. Popova, V.M., Abramov, E.P. Istomin, A.G. Sokolov, N.N. Popov, A.I. Levina, Proceedings of the 33rd International Business Information Management Association Conference, IBIMA 2019: Education Excellence and Innovation Management through Vision 2020, 8575-8579 (2019)

18. V.A. Zhigulsky, A.A. Ershova, M.B. Shilin, V.M. Abramov, 18th International Multidisciplinary Scientific GeoConference Surveying Geology and Mining Ecology Management, SGEM, Bulgaria 18(5.1), 423- 430 (2018)

19. S.I. Bidenko, E.P. Istomin, V.G. Burlov, V.M. Abramov, A.G. Sokolov, 19th International Multidisciplinary Scientific GeoConference Surveying Geology and Mining Ecology Management, SGEM Bulgaria 19(5.3), 139-145 (2019)

20. O.N. Mandryka, V.M. Abramov, A.A. Ershova, M.B. Shilin, Yu.L. Matveev, A.N. Chusov, N.N. Popov, Proceedings of the 33rd International Business Information Management Association Conference, IBIMA 2019: Education Excellence and Innovation Management through Vision 2020, 7173-7183. (2019)

21. L.N. Karlin, V.M. Abramov, A.A. Ovsiannikov, Oceanology 49(3), 327-330 (2009) 
22. N.N. Popov, R.I. Bachiev, V.M. Abramov, 16th International Multidisciplinary Scientific GeoConference Surveying Geology and Mining Ecology Management, SGEM, Bulgaria 4(2), 323-330 (2016)

23. J. Lednova, L. Karlin, O. Khaimina et al, 14th International Multidisciplinary Scientific GeoConference Surveying Geology and Mining Ecology Management, SGEM Bulgaria 2(3), 645-652 (2014)

24. A.I. Levina, A.A. Fokicheva, E.P. Golosovskaya, V.M. Abramov, E.P. Istomin, A.G. Sokolov, Proceedings of the 33rd International Business Information Management Association Conference, IBIMA 2019: Education Excellence and Innovation Management through Vision 2020, 8638-8642 (2019)

25. A.I. Levina, A.S. Dubgorn, O.Y. Iliashenko, Proceedings - 2017 European Conference on Electrical Engineering and Computer Science, EECS 2017, 351-355 (2018)

26. A.I. Klimin, N.V. Pavlov, A.M. Efimov, Z.L. Simakova, Proceedings of the 31st International Business Information Management Association Conference, IBIMA 2018: Innovation Management and Education Excellence through Vision 2020, 1669-1679 (2018) 